\title{
Seis enfoques en el estudio de la historia de la Psicología
}

Six Approaches in the Study of the History of Psychology

Recibido: 5 de marzo 2021, evaluado: 11 de marzo 2021, aceptado: 5 de abril 2021

\author{
Ramón León Donayre \\ https://orcid.org/0000-0002-3692-6986 \\ rld310850@yahoo.com.mx \\ Universidad Ricardo Palma
}

\section{Resumen}

Los cursos de historia de la psicología en las universidades están sufriendo una reducción (de dos semestres a uno). En el presente artículo el autor discute la importancia de las asignaturas de historia de la psicología y trata de los más importantes enfoques de la investigación histórica en psicología: el biográfico, el cronológico, el orientado a los problemas, el social, el contrafáctico y el de la historia de los aparatos.

Palabras clave: enfoques-historia de la psicología

\section{Summary}

The courses of history of psychology at the universities are suffering a reduction (instead two semesters only one now). In this communication the author discusses the importance of the history of psychology asignatures and shows the most important approaches to the historical research in psychology: the biographical, the chronological, the problem-oriented, the social, the contrafactic. and the history of apparats.

Key word: Approaches-history of psychology 


\section{Introducción}

Los cursos de historia de la psicología experimentan un retroceso en todos los programas de estudio a nivel de pregrado de la especialidad. Antes abarcaban dos semestres, ahora están siendo reducidos a uno. Hay quienes temen su total desaparición.

Eso no debe sorprendernos, dado que se inscribe en una tendencia de gran fuerza en nuestros días: las humanidades en general se encuentran en retirada de los planes de estudio (no solo de la psicología) (Nussbaum 2010), que cada día "se ajustan” más y, al hacerlo, "ajustician" a algunas asignaturas, consideradas como poco importantes o no conducentes a la gran meta: el profesional especializado.

Los planes de estudio son productos sociales (Martin 1981), y la sociedad moderna promueve la especialización y una visión pragmática de los estudios; muchos países enfrentan además problemas económicos que impactan en los presupuestos de las universidades. Todas aquellas asignaturas vistas como "poco prácticas" o "irrelevantes para el desempeño profesional" son de inmediato sometidas al severo rasero de la ratio "costo/beneficio" y, consecuentemente, "sacrificadas" en aras de la rapidez, la utilidad y el ahorro presupuestal.

Para algunos, los más optimistas, se trata de algo que durará un tiempo. Después se retornará a una "sana" consideración de la importancia de disciplinas "poco prácticas" como la historia, la literatura, e inclusive la filosofía. Quienes piensan así suponen que la complejidad del mundo moderno, los numerosos desafíos que ellos plantean, harán que, más temprano que tarde, los encargados de planificar programas de estudio se den cuenta de que, hoy más que nunca, esas especialidades no solo son necesarias sino hasta urgentes. Porque sin ellas, ¿cómo sería posible entender fenómenos tan alarmantes como el terrorismo, las guerras étnicas o problemas que generan tanta discusión como las uniones civiles o la eutanasia? ${ }^{1}$

Estos son fenómenos y problemas que demandan una perspectiva interdisciplinaria, la que a su vez exige el conocimiento de varias disciplinas, algunas de ellas consideradas

\footnotetext{
${ }^{1}$ Por ejemplo, Martha Nussbaum, una decidida defensora de las humanidades en estos tiempos difíciles para ellas, ha abogado por la enseñanza de la literatura en los programas de derecho (Nussbaum 1997).
} 
innecesarias por muchas autoridades universitarias ${ }^{2}$, como sucede con la antropología y la sociología ${ }^{3}$

Un ejemplo de eso lo tenemos en la "arabística", es decir, aquel conjunto de disciplinas que tienen como centro de interés el mundo árabe y que incluyen el conocimiento del idioma, la antropología, la historia, el derecho del mismo. ¿A quién, sino a un espíritu muy selecto, se le habría ocurrido estudiarla en Occidente hace unos 60 años? Hoy se reconoce que la cultura islámica ha jugado un papel decisivo en la constitución de la ciencia occidental y que, por ejemplo, Avicena ha sido tan importante como los grandes estudiosos europeos (Iaccarino 2003). Tanto la industria (la petrolera especialmente) como los servicios diplomáticos y de inteligencia de muchos países occidentales requieren de especialistas en el mundo y la cultura árabes (Valosik 2014). Peter Scholl Latour (1924-2014), destacado periodista germano, fue uno de ellos. Sus libros (i. e. Scholl Latour 2002) y comentarios sirven como valioso material de análisis para expertos y de información para neófitos. En un nivel más académico podemos mencionar a Edward Said (1935-2003), cuyo libro Orientalismo (Said 2003) ha sido de gran influencia en deconstruir mitos y prejuicios acerca del mundo islámico

Otros, los pesimistas, piensan que ya no hay retorno y se preparan para la defensa radical de los pocos espacios en los cuales las humanidades todavía están presentes. Un reducto de ellas son los estudios culturales, un área no siempre comprendida por la sociedad (Payne 2002).

El futuro, como siempre, dirá quiénes son los que tienen la razón.

Lo cierto es que hay disciplinas en las cuales las humanidades y, en particular, la historia, tienen poco espacio e inclusive hasta poco sentido: ¿alguien ha visto en el programa de estudios de la especialidad de Ingeniería de Sistemas o de Ingeniería Electrónica algún curso que trate de la historia de ellas? Y si existiera, ¿qué sentido tendría? Ambas son especialidades de tan rasante desarrollo y tan reciente existencia que lo mejor es dejar que transcurran algunos

\footnotetext{
${ }^{2}$ Así, por ejemplo, los psicólogos interesados en los temas de equidad, hoy tan actuales, deberían leer Teoría de la justicia, de John Rawls (1995).

${ }^{3}$ A mediados del 2015 Habukun Shimomura, Ministro de Educación del Japón, pidió a las universidades de ese país cerrar sus departamentos de humanidades y ciencias sociales o convertirlos en programas que promovieran mejoras sociales.
} 
buenos años hasta que alguien se siente a hacer un recuento histórico de ambas; al fin y al cabo, para que haya historia tiene que haber un pasado, y este debe ser largo.

Eso es lo que más o menos ocurre con esas especialidades, y por eso no debe asombrarnos que la historia de ellas sea inexistente o se circunscriba más bien a comentarios de sobremesa de algún especialista con intereses que se extiendan más allá de sus nichos de saber. Además, hay que preguntarse en qué contribuirían los estudios históricos a resolver los problemas que pudieran enfrentar las especialidades antes mencionadas. La respuesta parece evidente: en nada o en muy poco.

Pero hay otras especialidades y ciencias en las cuales los cursos de historia no pueden faltar. Y no pensamos solo en la psicología. Tomemos en consideración a la "princesa" (tal vez la reina, en realidad) de las así llamadas ciencias sociales: la economía. La "historia del pensamiento económico" es una asignatura obligatoria ${ }^{4}$, más aún ahora que muchos economistas considerados muertos "han resucitado": Marx no es, por cierto, el único caso, pero sí el más dramático. Otro ejemplo es Keynes (véase Skidelsky 2010).

Pensamos asimismo en la medicina, en cuyo programa de estudios no falta un curso dedicado a su historia. De hecho, muchas de las más prestigiosas universidades norteamericanas y europeas tienen institutos dedicados a la historia de la medicina. Dos de los más reputados historiadores de la medicina en el pasado fueron Karl Sudhoff (1853-1938), el más importante en su época, y Henry E. Sigerist (1891-1957). En nuestros días destacan Wolfgang U. Eckart (i. e. Eckart \& Jütte 2007), en Alemania, y John C. Burnham (1929-2017), en los Estados Unidos de Norteamérica (i. e. Burnham 2005).

Y si dentro de la medicina nos acercamos a la psiquiatría, encontraremos que esta especialidad tiene el privilegio de contar con numerosos textos dedicados a su historia. En realidad, escribirlos es toda una industria bibliográfica desde el pequeño libro de Erwin $\mathrm{H}$. Ackerknecht (1906-1988), Breve historia de la psiquiatría (Ackerknecht 1964), hasta la Historia de la psiquiatría compilada por Postel y Quétel (1987). Hay algún caso, inclusive, en

\footnotetext{
${ }^{4}$ Como lo es el curso de Derecho Romano en la formación de los abogados.
} 
que el prestigio de un autor se basa en un libro de naturaleza histórica: Henri F. Ellenberger (1905-1993) y su clásico El descubrimiento del inconsciente (Ellenberger 1976) ${ }^{5}$.

¿Qué pasa con esas ciencias, con la economía, el derecho, la medicina? La respuesta más sencilla puede ser que los grandes temas de los que tratan (pobreza y riqueza, para mencionar los dos más prosaicos en el mundo de la economía; justicia, en el derecho; y, salud y enfermedad, en el caso de la medicina) siguen sin tener hoy una visión que satisfaga a todos; al menos una definición unánimemente aceptada. Por el contrario: las discusiones continúan a pesar de los mil análisis y los cientos de planteamientos. Y probablemente proseguirán hasta el día del juicio final ${ }^{6}$.

Veamos el caso de la psiquiatría: aun hoy, a estas alturas de la historia de la humanidad, no contamos con una definición satisfactoria acerca de la salud mental y de la enfermedad mental (Heinz 2014); todavía nos seguimos enfrascando en controversias sobre si normalidad y salud mental son sinónimos o antónimos, y para entender la normalidad contamos con numerosos criterios (muchos de ellos contrapuestos entre sí). Hay inclusive, quien, como Thomas Szasz (1920-2012), se atrevió a cuestionar el concepto de enfermedad mental (Szasz 1961).

Los cursos de historia de la especialidad siempre han tenido un espacio en los programas de formación de psicólogos. Y lo seguirán teniendo, sin duda, aunque su presencia quede reducida a solo una asignatura de cuatro horas. Cada nueva generación de estudiantes de psicología escucha en sus clases de teorías de la personalidad y de la motivación nombres como los de Freud, McDougall, Maslow y Allport, así como se entera de Ebbinghaus y Pavlov en la asignatura de psicología del aprendizaje, y de Klineberg en las de psicología social. Todos estos autores (y muchos más) son así "redescubiertos" y, en muchos casos, para que ese redescubrimiento sea adecuadamente elaborado por los estudiantes es necesaria la información histórica. No solo de la psicología, por cierto; también de la sociedad de su época.

\footnotetext{
${ }^{5}$ No olvidemos al peruano German Berrios, en Cambridge, Gran Bretaña, distinguido historiador de la psiquiatría y editor de History of Psychiatry, la más importante revista de la especialidad.

${ }^{6}$ Agreguemos a estos temas que generan tanta controversia, otros con no menor potencial ígneo, que demandan un análisis histórico: ¿qué significado tenía el trabajo en el siglo XVI y qué significado tiene hoy? ¿qué significaba salud mental y normalidad en el siglo XIV, en el XVIII, y qué significa hoy? Esto, solo para mencionar dos ejemplos. Julian Jaynes trató sobre otros temas en su desafiante libro El origen de la conciencia en la ruptura de la mente bicameral (Jaynes 1987).
} 
De otro lado, la producción bibliográfica referida a la historia de la psicología es asimismo impresionante (e. g. Graumann \& Gergen 1996, Leahey 2005, Jacó-Vilela et al., 2005, Pickren \& Dewsbury 2007, Hergenhahn 2011, Valsiner 2012), y no cesa. Hay revistas especializadas de amplia circulación internacional (Journal of the History of the Behavioral Sciences, History of Pychology, Revista de Historia de la Psicología) ${ }^{7}$. Y hay también un importante número de especialistas agrupados en sociedades científicas (División 26, History of Psychology, de la American Psychological Association, Sociedad Española de Historia de la Psicología, etc.).

La reflexión y la investigación históricas son una de las formas de la investigación básica (Pongratz 1984), que no constituyen un lujo sino una necesidad. Así lo reconoce el que desea iniciarse en el estudio de un área que hasta ese momento le es desconocida, como también aquel que comienza a reunir material para su tesis de licenciatura, maestría o doctorado. La investigación histórica tiene su inicio ya cuando el que se quiere graduar comienza por investigar qué se ha escrito, qué se ha publicado, qué se ha aceptado o descartado en el tema sobre el cual habrá de escribir su tesis.

Pero la historia tiene sus bemoles. Y no solo la de la psicología, sino también las "historias" de todas las ciencias. Esos bemoles tienen que ver, entre otras cosas, con los enfoques.

Hay quien hace historia de una manera y quien la hace de otra. Hay quien ve los temas desde un ángulo y quien los ve desde otro. Y hay quienes, al analizar el mismo fenómeno, llegan a conclusiones contrapuestas. No es un tema de historia de la ciencia, sino uno muy doloroso en la historia del Perú, pero sirve de ejemplo para lo que queremos decir: los análisis históricos sobre la Guerra del Pacífico. Léanse, a guisa de ilustración, las historias de este conflicto escritas por chilenos, peruanos, bolivianos y extranjeros, y se tendrá una clara idea de lo que estamos diciendo (véase por ejemplo Sater 2007, Farcau 2000, Cluny 2008).

En la historia de la ciencia hay varios enfoques. El más antiguo y el que genera más atractivo entre el gran público es el de las grandes personalidades, o de un modo menos pomposo, el enfoque biográfico.

\footnotetext{
${ }^{7}$ Debe mencionarse asimismo la Sociedad Peruana de Historia de la Psicología, que anima desde Arequipa el Dr. Walter Arias, de la Universidad San Pablo de esa ciudad.
} 


\section{El enfoque biográfico}

Sin duda alguna, hay un trasfondo romántico que hace que ese enfoque conserve aun hoy vigencia. El biografiado o la biografiada es alguien que despierta la curiosidad, incita la atención del que escribe su biografía. De otro modo no podría entenderse el cúmulo de esfuerzos, el número de horas, la incesante búsqueda de detalles y de nueva información y la comprobación de la misma que son desplegados a la hora de escribir la biografía de alguien, que tiene que ser alguien importante para el que decide adentrarse en su vida.

No hay año en que no aparezca, por ejemplo, una nueva biografía o un artículo biográfico de Newton, el científico por excelencia. Este genio inglés, que hoy probablemente correría el riesgo de ser internado en un sanatorio mental, ejerce, a pesar de tantos siglos transcurridos desde su paso por este mundo, un raro y permanente atractivo entre nosotros, como lo demuestra la abundancia de escritos que tratan acerca de su obra, pero sobre todo acerca de él (Westfall 2006, Keynes 1995).

Los estudios biográficos sobre Darwin abundan también, y van desde los muy serios y rigurosos (como por ejemplo los de Browne 2009) hasta los teñidos por una perspectiva psicoanalítica (Bowlby 1990). Y ni hablar de la inmensa literatura dedicada a Sigmund Freud. Una verdad casi absoluta: todo aquel que escriba sobre el padre del psicoanálisis tiene asegurada lectoría. No importa que trate de temas profundos o de cuestiones de menor trascendencia, o hasta de anécdotas al estilo de "mi encuentro con Sigmund Freud" o "una hora en el diván en Berggasse XIX”. Da lo mismo: siempre habrá quien lo lea ${ }^{8}$.

No podemos, ciertamente, dejar de mencionar de Albert Einstein, el arquetipo del científico en el siglo XX. La literatura sobre él es asimismo abundante: una biografía suya no muy antigua ha tenido (y tiene) una amplia lectoría (Isaacson 2008). No hay tema de su vida,

\footnotetext{
${ }^{8}$ El interés por la persona y la vida de Freud ha dado lugar a la aparición de "productos colaterales", como es el de la gran cantidad de biografías dedicadas a discípulos y disidentes de Freud y hasta a sus pacientes, como es el caso de Les patients de Freud (Borch-Jacobsen 2011).
}

Parece justificado preguntarse si alguien hubiera escrito una biografía de Viktor Tausk, Herminie Hug-Hellmuth o de Otto Rank, si estos no hubieran militado en las filas del psicoanálisis en sus inicios. 
de sus ideas, de sus andanzas, que no haya sido abordado; algún libro trata hasta de sus viajes (Eisinger 2011) ${ }^{9}$.

Durante muchas décadas este enfoque fue el predominante y se caracterizó por presentar a los biografiados como seres casi sobrenaturales, verdaderos genios que, a fuerza de talento y trabajo, vencieron la mediocridad ambiente que los rodeaba.

No siempre esas biografías tenían un final feliz, en donde "los buenos" triunfan (Darwin y Freud, digamos). A veces el fin era doloroso, como en los casos de Semmelweis y Turing ${ }^{10}$. Pero, igual, lo central era que todo giraba en torno a las grandes personalidades. El lector desavisado de muchas biografías era "capturado" por la personalidad imponente del protagonista perdiendo de vista el entorno social, la época, el entramado de ideologías, creencias, expectativas y prejuicios, que son el escenario en el cual la vida de todos, genios o medianos, se desenvuelve.

Algunas biografías eran descaradamente románticas. Así, la de Freud escrita por Ernst Jones (Jones 1976), mirada hoy con gran suspicacia y considerada más una hagiografía: nadie, tampoco Freud, puede ser un hombre tan dotado de bondad, intuiciones y genialidad como es el que nos presenta Jones en las páginas de su voluminoso libro ${ }^{11}$.

Sin embargo, en ocasiones las biografías han tenido un efecto desenmascarador que ha conmovido los cimientos mismos de ciertas ciencias. Eso es lo sucedido con la de Cyril Burt

\footnotetext{
${ }^{9}$ Creemos, sin embargo, que el público en general se siente más atraído hacia una biografía de Freud que por una de Einstein. Una razón para ello estriba en los temas que abordaron uno y otro: resulta difícil para un lector cualquiera seguir y entender el curso y la naturaleza de las ideas de Einstein, pero no así las de Freud, que no solo explora los recovecos de nuestra vida psicológica, sino que además trata de temas de naturaleza inmediata a nosotros, como la vida cotidiana, los sueños, los chistes. Todo esto, además, en un estilo ameno y suasorio.

${ }^{10}$ Es interesante anotar que estos dos personajes, Semmelweis y Turing, han sido objeto de novelas y de películas, lo que demuestra lo original de sus existencias, trágicamente interrumpidas, y el aura romántica que rodea a sus recuerdos. Semmelweis es el personaje de una novela del mismo nombre de Louis-Ferdinand Celine (1968) en tanto que Turing ha sido el protagonista de una reciente película, Código Enigma.

${ }^{11}$ Lo mismo puede afirmarse de la que tal vez es la primera biografía latinoamericana del padre del psicoanálisis, escrita por el psiquiatra peruano Honorio Delgado y publicada en 1926 (Delgado 1926). Su lectura nos da una idea de la admiración que profesaba su autor por Freud, la misma que años después desaparecería para dar lugar a una visión muy severa de él (Alarcón 1982).
} 
(1883-1971) preparada por Hearnshaw (1979) ${ }^{12}$, cuyas páginas contenían revelaciones desconcertantes; verdadero material explosivo, podríamos decir.

Una sensación de injusticia surge en muchos cuando se verifica que existen decenas (por no decir cientos) de biografías de personajes de luminaria, como Darwin y Freud, pero que contemporáneos suyos, colaboradores en unos casos y opositores en otros, a los que ellos hacen referencia en sus escritos, apenas han sido objeto de interés biográfico: sobre Josef Breuer, el acompañante de Freud en sus primeros años, apenas se ha escrito una biografía $\left(\right.$ Hirschmüller 1990) ${ }^{13}$. Lisa Meitner, la colaboradora cercana de Einstein, ha sido injustamente ignorada.

Pero en los últimos años las biografías, fundadas en investigación sólida, han vuelto a ganar espacio. El acceso a archivos personales, las técnicas de la historia oral, la discusión y consideración de la información obtenida no solo con los familiares sino también con colegas, discípulos, amigos y hasta enemigos del biografiado, pero asimismo con sociólogos, psicólogos e historiadores, así como el hecho de que algunos de los biografiados condujeran una "vida biográfica" (término propuesto por Söderqvist 2003), conservando hasta la última de sus notas escritas, fotos, recibos, han posibilitado biografías más serias, más rigurosas: la de Erikson y la de Kinsey por ejemplo (Friedman 1999, Jones 1997), como también la de Helmholtz (Meulders 2010) $)^{14}$.

${ }^{12}$ Cyril Burt (1883-1971), una de las grandes personalidades de la psicología inglesa de la primera mitad del siglo XX, y defensor prominente de la posición genetista en materia de la inteligencia, fue acusado póstumamente de haber cometido fraude en numerosos trabajos con los que apuntalaba esa posición (Kamin 1983). Hearnshaw, encargado de escribir una biografía de él, dio claro sustento, basándose en sus averiguaciones a esa acusación.

Algo semejante puede decirse de The creation of $\mathrm{Dr}$. B., la biografía de Bruno Bettelheim, el famoso psicoanalista vinculado al tratamiento del autismo infantil, escrita por Pollack (2014). Science as autobiography: the troubled life od Niels Jerne (Soderqvist 2003), nos ofrece una imagen sorprendente, perturbadora, casi inimaginable, del gran inmunólogo danés que recibiera el Premio Nobel de Medicina en 1984.

13 "Se conoce poquísimo de la vida de Josef Breuer (1842-1925) y lo poco es por fuentes indirectas no verificables o su polémica asociación con Freud. Conocedor del griego, como investigador fue sobresaliente en el área de la fisiología experimental y al retirarse ejerció como reputado médico privado" (Figueroa 2014; pg. 265). Anotemos, de otro lado, que la famosa paciente "Anna O.", protagonista del primer caso tratado con el naciente método del psicoanálisis, no fue tratada por Freud sino por Breuer, como lo ha señalado Borch-Jaconsen (2011).

${ }^{14}$ En el caso de Freud, la biografía preparada por Peter Gay (1989) es un trabajo de primer nivel. A esa obra podemos agregar la escrita por Roudinesco (2015), asimismo de excelente factura, y Becoming Freud. The making of a psychoanalyst (Phillips 2014). 
En ellas se ha minimizado o ha desaparecido el recurso a la anécdota y la "visión de abajo a arriba" (propia de quien se acerca con veneración a un genio) que caracterizaban a muchas biografías de antaño, cobrando importancia más bien el detenido (a veces obsesivo) estudio de cartas, documentos oficiales, artículos académicos y periodísticos, y la examinación de la vida, logros y fracasos del biografiado en el contexto de su época y de su sociedad ${ }^{15}$. Un excelente ejemplo de esto lo constituye la reciente biografía de Pavlov proveniente de la pluma de Todes (2014) ${ }^{16}$, así como la de Hermann Lotze (Woodward 2015).

Aún algo más. Debido al gran interés contemporáneo por la creatividad, los estudios biográficos han dado decisivo impulso a este enfoque y viceversa. Howard Gardner los ha empleado para ejemplificar su teoría de las inteligencias múltiples, como lo demuestra su libro Mentes creativas (Gardner 1995), al que habría que agregar Mentes líderes (Gardner \& Laskin $1998)^{17}$.

En la reivindicación del enfoque biográfico en la historia de la ciencia (y por supuesto también en el de la psicología) no puede obviarse la mención a una figura fundamental: Charles C. Gillispie, el director en jefe del gran proyecto que culminara en la publicación de ese verdadero monumento historiográfico que es el Dictionary of scientific biography (Gillispie 1970-1980).

Muy criticado en el momento de su concepción y durante los primeros avances por historiadores escépticos, feministas y científicos cansados de las biografías laudatorias, el Dictionary of scientific biography, como monumental realidad concluida gracias al aporte de científicos e historiadores de la ciencia de las más diversas latitudes, sentó nuevos estándares para las biografías de científicos: precisión informativa, sustento documental verificado y sólido respaldo bibliográfico, exposición sobria de hechos y circunstancias, suposiciones y

\footnotetext{
${ }^{15}$ En muchas de estas biografías de nuevo y más riguroso cuño pueden reconocerse las reglas propuestas por Ellenberger y que en realidad valen para todo trabajo de investigación: ubicar todo en su contexto, separar los hechos de la interpretación, verificar todo y no dar nada por real sin haberlo verificado. Pensamos por ejemplo en biografías recientes de Eysenck (Corr 2016) y Meyer (Lamb 2014), así como la de la antropóloga Cora Du Bois (Seymour 2015).

${ }^{16}$ Un comentario amplio de esta obra se encuentra en León (2016-2017).

${ }^{17}$ Su libro Mentes creativas tiene como subtítulo "Una anatomía de la creatividad vista a través de las vidas de: Sigmund Freud, Albert Einstein, Pablo Picasso, Igor Stravinsky, T. S. Eliot, Martha Graham, Mahatma Ghandi”. En efecto, la obra contiene breves y amenas biografías de cada uno de ellos. En Mentes líderes los protagonistas son Margaret Mead, J. Robert Oppenheimer, Robert Maynard Hutchins, Alfred P. Sloan, George C. Marshall, Papa Juan XXIII, Eleanor Roosevelt, Martin Luther King, Margaret Thatcher, Jean Monnet y Mahatma Gandhi.
} 
especulaciones formuladas en los límites cercanos a la verosimilitud, y, por supuesto, nada de magnificaciones de logros como tampoco de idealizaciones de personas y de existencias.

\section{El enfoque cronológico}

La historia, la de la psicología y la de cualquier ciencia, y también la de cualquier individuo, son realidades inexorablemente vinculadas a tiempos. Cualquiera que desee estudiarlos debe ordenarlos. Y ese orden tiene que ser en primera instancia cronológica. La inmensa mayoría de textos de historia de la psicología sigue ese enfoque, que permite ordenar e hilvanar los acontecimientos y que lleva de la mano al lector en un viaje a través del tiempo.

Un ejemplo de este enfoque lo constituye A chronology of noteworthy events in American psychology, obra de Street (1994). También nos parece digno de citarse Geschichte und Systematik der Psychologie (Schönpflug 2000).

El enfoque cronológico busca responder a cuatro preguntas: ¿cuándo?, ¿cómo?, ¿quién? y ¿dónde?

Absolver estas preguntas es indispensable porque ubicar a personas en el tiempo y en el espacio y así poder valorar lo hecho o lo omitido, lo logrado o lo olvidado, no con los ojos de hoy sino con empatía hacia quien vivió, digamos en el siglo XVIII o XIX es un mínimo acto de equidad que permitirá entender lo sucedido.

El enfoque cronológico en su versión moderna nos ofrece lo que hoy día llamamos una línea del tiempo. Y a veces se reduce solo a eso: a una línea del tiempo, valiosa como recurso didáctico, pero insuficiente para entender la evolución de la psicología, la cual no se limita solo a los tiempos como tampoco se circunscribe solo a las personas.

En ocasiones, quienes elaboran "líneas del tiempo" de una ciencia en una columna agregan otra en la cual se enumeran algunos de los principales hechos sociales de la época. Por ejemplo, en la línea del tiempo de la química puede colocarse fines del siglo XVIII y el nombre de Lavoisier, y en la de los hechos sociales una referencia a la Revolución Francesa y, más específicamente, a la época del Gran Terror.

El enfoque cronológico de la historia de la psicología como el de cualquier otra ciencia no solo debe tomar en cuenta lo que ocurre en cada una de ellas, sino también lo que sucede en 
torno a ella en cada momento, en cada sociedad; porque no olvidemos, la ciencia es una creación social.

Uno de los más graves peligros del enfoque cronológico es que puede despertar en el estudioso la errada suposición de que muchos fenómenos sociales y logros académicos tienen una fecha de nacimiento precisa. Lo cierto es que, cuanto más complejo y/o revolucionario es un fenómeno, descubrimiento o invención, tanto más sus orígenes deben ser buscados no en la fecha precisa sino años o hasta décadas antes.

Este peligro proviene de la naturaleza muchas veces no analítica inherente a este enfoque. Asumiendo el riesgo de la exageración, podemos decir que en muchos casos este enfoque tiene el perfil de un informe, en el cual aparecen nombres de personas, ciudades e instituciones, fechas, lugares, títulos de libros, editoriales, pero nada más.

Bien es verdad, sin embargo, que contar con los nombres, las ciudades, las fechas y lugares correctos, es un muy valioso punto de inicio para nuestras investigaciones, como lo podemos verificar cuando obtenemos esa información en enciclopedias y diccionarios.

\section{Enfoque doxográfico}

Otro enfoque va de lo personal a lo conceptual: el doxográfico. En este enfoque no importan las personas, sino las ideas; ellas son las verdaderas protagonistas. Y en esto la psicología nos ofrece una verdadera multitud de ejemplos.

¿Qué significa, por ejemplo, la palabra yo cuando la emplea Freud y qué significado tiene cuando la emplea Gordon W. Allport? ¿qué significa la palabra psicología en el siglo XVIII y qué en el siglo XX y en el XXI?, ¿por qué algunos conceptos han partido de la psicología, al parecer para no volver más, como carácter, por ejemplo, y por qué otros "van y vienen", como temperamento o genio? Inclusive la palabra pasión pareciera anunciar su retorno (véase el excelente libro de Bordelois 2006): ¿qué ha pasado?, ¿cuáles han sido las vicisitudes de esos términos?

El enfoque doxográfico de la historia de la psicología es el de la historia de sus problemas y controversias. Y qué duda cabe que tres o cuatro de las más importantes palabras 
que un psicólogo puede emplear (motivación, personalidad, inteligencia, normalidadanormalidad) están todas preñadas de múltiples significados y rodeadas de controversias.

Ha habido y hay controversias con un escenario en el cual los representantes de las posiciones antagónicas estaban frente a frente, mirándose a los ojos y formulando una réplica para cada argumento del opositor. Por ejemplo, la que sostuvieron William McDougall y John B. Watson el 5 de febrero de 1924 en The Psychological Club en la capital de los Estados Unidos de América.

Pero otras controversias han ocasionado un ingente gasto de papel y tinta, como las que sostuvo Wilhelm Wundt con Carl Stumpf, Karl Bühler y Oswald Külpe, en diferentes años.

Podría uno creer que las polémicas sostenidas a través de las páginas de las revistas tienen un tono menos incisivo y agresivo que aquellas sostenidas frente a frente. Crasa equivocación: quien lea, por ejemplo, la controversia entre Wundt y Stumpf podrá reconocer cómo el tono y la naturaleza de los argumentos esgrimidos van volviéndose más agresivos.

Y hay, por supuesto, polémicas que no tienen fin, como la de nature-nurture.

Estudiarlas desde la perspectiva histórica permite revivir cada época y entender el drama que los psicólogos enfrentaron en cada una de ellas. Y eso es absolutamente necesario, porque de otro modo no podemos hacer justicia a lo que cada cual dijo o no dijo, vio o no vio, intuyó o dejó de intuir.

El protagonista de la ciencia es el científico. Una ciencia sin él es inimaginable, absolutamente imposible. Pero, también lo es una ciencia sin problemas, pues estos son los que atizan la curiosidad y las ambiciones del científico.

El enfoque doxográfico permite además contextualizar los problemas de la psicología. ¿Nos hemos preguntado por qué los psicólogos le damos hoy tanta importancia al tema de la creatividad? Resulta fácil entender, en un mundo en el cual las personas alcanzan elevadas edades, por qué el campo de la psicología gerontológica experimenta un gran desarrollo, pero es algo más complicado el entender por qué el tema de la equidad va ganando cada vez más significado en la investigación psicológica. O por qué en los últimos años han aparecido tantos libros dedicados a estudiar el tema de la envidia (entre otros, por ejemplo, Reidl Martínez 2005, y Smith 2008). 
Cada época tiene sus problemas, que aborda e intenta solucionar con las herramientas conceptuales (y hasta físicas) que tiene a su alcance. La geometría de los Elementos de Euclides ha sido durante varios siglos la base de la física, la química y la astronomía, pero sirvió asimismo para que en el siglo II se elaborara la teoría ptolemaica del universo. La Biblia era en la Edad Media una obra de permanente consulta y obsesivo estudio para muchos filósofos naturales. Nos sorprendería ver la frecuencia con la cual Newton la estudió ${ }^{18}$.

Hay algo más. Una cosa interesante en la historia del saber psicológico es que primero han aparecido los problemas y demandas sociales, y después la psicología (pero no solo ella, también la sociología y la antropología, para solo mencionar dos disciplinas cercanas) ha comenzado a estudiarlos y a desarrollar-como ha podido, a veces bien y en otras erradamenteenfoques y perspectivas de análisis. Eso sucede hoy con el tema del terrorismo y ha sucedido en el pasado con el feminismo, la revolución sexual y, más recientemente, con la despatologización de la homosexualidad.

Estos problemas, o mejor dicho estos fenómenos históricos, sorprendieron a la psicología como un ladrón nos sorprendería si entrara a nuestra casa en la madrugada. A partir de su presencia, los psicólogos comenzaron a tratarlos y a buscar que entenderlos ${ }^{19}$.

\section{El enfoque social}

Esto nos lleva al tercer enfoque, el social, que ha sido promovido por historiadores marxistas, pero no solo por ellos.

Como doctrina política, enterrado; como metodología de estudio e interpretación el marxismo continúa teniendo vigencia, si bien relativa. Marx promovió la mirada más allá de lo evidente, el examen del contexto y en especial del contexto económico. Hay excelentes

\footnotetext{
18 "Newton escribió mucho acerca de la Biblia como un documento histórico, acerca de la precisión de la cronología bíblica y acerca del mensaje de la Biblia. Todos estos fueron temas de gran importancia durante el siglo XVII. Newton escribió sobre ellos desde sus años de estudiante en Cambridge hasta su muerte. Por muchos años, incluyendo los centrales en su carrera intelectual, Newton escribió sobre estos temas" (Popkin 1990; pg. 103).

${ }^{19}$ Recuérdese, por ejemplo, que los libros más importantes sobre la identidad femenina, mucho antes de que los psicólogos la abordaran, fueron El segundo sexo, de la pensadora francesa Simone de Beauvoir (1949), y El cuaderno dorado, de Doris Lessing (1978), la novelista inglesa.
} 
ejemplos de estudios influidos por la perspectiva marxista, como el de la historia de la ciencia escrita por Bernal (1967).

$\mathrm{Y}$ es que las ciencias no aparecen en el aire ni de la nada. Se habla mucho de las paternidades científicas: Hipócrates como padre de la medicina, Herodoto como padre de la historia, y Wundt de la psicología. Se trata de ficciones o, en el mejor de los casos, de metáforas. Las ciencias no tienen ni padre ni madre sino contextos que las favorecen o impiden su desarrollo. Sin la atmósfera cultural de la primera mitad del siglo XIX, con la presencia del positivismo, el empirismo, el materialismo, el evolucionismo y el romanticismo, y el progreso experimentado por la fisiología y los desarrollos de la estadística, difícilmente habría surgido la psicología experimental.

En el caso de la psicología también hay estudios sociales de su historia. Lo que sucede es que muchas veces el análisis histórico desde la perspectiva marxista ha estado sazonado por calificativos que lo han terminado haciendo "poco apetitoso": Yarochevsky (1979), un importante historiador soviético de la psicología, fue siempre mirado con suspicacia por sus pares occidentales, por su insistencia en calificar in totto como idealista y burguesa a la psicología occidental.

Materia prima para estudiar el contexto social la hay en abundancia en la psicología. La decadencia de la psicología alemana durante los años del nacionalsocialismo al mismo tiempo que su insistencia en sustentar las ideas de Hitler, el surgimiento de la psicología soviética, son solo dos de los temas que han sido abordados desde el enfoque social, pero no necesariamente con los parámetros del marxismo ${ }^{20}$.

El gran problema de la interpretación marxista de la historia de la psicología ha sido su naturaleza unilateral y su vocación excluyente, ambas sazonadas de modo generoso con ataques o, en el mejor de los casos, por errores de facto o de valoración de lo ocurrido en la psicología occidental. Afirmar que el conductismo y el neoconductismo son herramientas del imperialismo puede impactar en oídos crédulos, pero no en quienes esperan una interpretación más diferenciada de la historia de la psicología.

\footnotetext{
${ }^{20}$ Geuter (1992) acabó con el mito de que la psicología había sido una de las víctimas de Hitler, demostrando por el contrario que muchos psicólogos alemanes se pusieron al servicio de la ideología nazi. Kozulin (1984) ha estudiado el origen de la psicología soviética, y Ash (1998) el de la psicología de la Gestalt.
} 


\section{El enfoque contrafáctico}

Tenemos otra perspectiva, por cierto, un poco inusual. La del azar en la historia de la ciencia. Tema poco tratado, es verdad. O quizás, más bien, abiertamente esquivado.

El azar ingresó a la vida académica con el provocativo libro de Jacques Monod (19101976), El azar y la necesidad (Monod 1970), y se encuentra también presente en la teoría de los juegos desarrollada por von Neumann y Morgenstern (von Neumann \& Morgenstern 1943). En el Perú no puede dejar de mencionarse El azar en la historia y sus límites (Basadre 1973), del gran historiador Jorge Basadre (1903-1980).

El azar en el mundo moderno ha sido "domesticado". Pero no plenamente. El existe, si bien el control que ejerce en nuestras vidas y destino va disminuyendo ostensiblemente. Pero hay casos de azar en la ciencia que vale la pena investigar. Y no nos referimos a la famosa manzana de Newton que, bien lo sabemos, es solo una metáfora cuando no una falsedad tan cruda que ofende.

Los descubrimientos de Pasteur, Fleming y Jenner, que han terminado salvando tantas vidas, son una buena demostración de la presencia del azar en el mundo de la ciencia, si bien en esta recibe el nombre de serendipia.

La así llamada historia contrafáctica es un modo de reconsiderar lo ocurrido tomando en consideración alternativas a lo que realmente ocurrió, es decir acercándose a ese ámbito propio del $\operatorname{azar}^{21}$.

¿Qué habría pasado si Freud no hubiera sido judío, sino un integrado ciudadano de la comunidad vienesa de su época?, ¿y si, en lugar de seguir el consejo de Brücke de alejarse de la vida académica por su condición de judío, hubiera persistido en su empeño de hacer carrera en la Universidad de Viena? ¿Quién habría conocido a Adler y a Jung si no hubieran entablado relaciones primero amistosas y discipulares y después de abierta enemistad con Freud? ¿Habrían llegado a ser conocidas las ideas de Mendel, si Courrens, DeVries y Tschermak no hubieran tomado conocimiento de su obra? ¿Qué hubiera sucedido con la teoría del ciclo vital

\footnotetext{
${ }^{21}$ El término ucronía, creado por Charles Renouvier en 1857 como un equivalente temporal de utopía, puede ser considerado un sinónimo. La ucronía es "lo que hubiera pasado si ..." y supone la posibilidad de un cambio radical de la historia por la más ligera desviación de su curso conocido en un momento determinado" (Renouvier 1945, vol. 2, 844-845).
} 
de Erikson, si este no hubiera emigrado a Estados Unidos? ¿Cuál habría sido el destino de la Psicología de la Gestalt de no haber aparecido Hitler en la Alemania de los años 1930? ¿Cómo habría evolucionado el conductismo si John B. Watson hubiera seguido activo en la psicología académica hasta el fin de sus días?

Si el historiador que emplea el enfoque biográfico requiere tener empatía con el personaje que estudia, y si debemos esperar meticulosidad y precisión de aquel que elabora una cronología, en el historiador contrafáctico se requiere todo lo anterior, pero, además, capacidad imaginativa para responder preguntas del tipo “¿y qué habría sucedido si...?”

Dadas las exigencias que plantea la historia contrafáctica y el hecho de que ella juega con la manipulación de alternativas, resulta comprensible que no despierte mucho entusiasmo entre los interesados por la historia de la psicología. Hay quienes la ven como un pasatiempo, o un producto de esta época, en la que se especula, se cuestiona, se relativiza todo, desde lo sagrado hasta lo pedestre ${ }^{22}$.

Particularmente ácida ha sido la crítica proveniente de las canteras del marxismo, doctrina que no admite que casualidades y acontecimientos fortuitos puedan cambiar el curso de los hechos.

Sería bueno, sin embargo, enterarnos de que la historia contrafáctica puede mirar a una larga existencia vinculada a algunos de los grandes nombres de la historia. Nada menos que Tito Livio, el gran historiador romano, formula preguntas que siguen el esquema de "¿y qué habría sucedido si...?". Y también encontramos reflexiones que siguen esta línea de entender y analizar la historia en Herodoto, Tucídides y Tácito.

Pero hay más. Como toda ciencia, la psicología también ha estudiado y tratado de explicar y controlar el azar. Freud apenas hace referencia al mismo, y cuando lo hace es para negarlo (véase su Psicopatología de la vida cotidiana, Freud 1968) pero Jung, tan audaz como él, sí buscó que explorarlo y explicarlo, y acuñó el término de sincronicidad en ese empeño.

\footnotetext{
${ }^{22}$ De hecho, las historias contrafácticas tuvieron su hora estelar en los años finales del siglo XX y los primeros del XXI. Entre otros, Niall Ferguson organizó un libro titulado Historia virtual, en el cual los Estados Unidos no se independizan, Alemania gana la Primera Guerra Mundial, etc. (Ferguson 2011). Véase Fraga (2016).
} 
De otra parte, la consideración del azar en los estudios psicológicos se expresa en los famosos "p" que suelen aparecer en el tratamiento estadístico incluido en la gran mayoría de reportes de investigación.

Investigar la influencia del azar en la psicología y en la ciencia en general es un verdadero desafío, porque la historia estudia lo que pasó, no lo que pudo pasar. Pero resulta siempre interesante hacerlo porque nos libera de esa visión conformista de que las cosas son como tenían que ser, olvidando que al lado de las grandes personalidades y de los importantes contextos sociales siempre están presentes la casualidad y lo imprevisto.

Considerar el azar permite especular, en el mejor sentido del término. Y todos sabemos que la ciencia tiene sus más remotos orígenes en la especulación.

\section{El enfoque de los aparatos}

Toda ciencia tiene métodos y técnicas. La medicina los tiene, también la sociología. Pero algunas además tienen aparatos, es decir instrumentos físicos, casi siempre de metal, creados para obtener información y, en muchos casos, obtenerla con gran precisión.

Para seguir con el ejemplo de la medicina, podemos decir que un capítulo muy importante de su historia es el referido a la historia de sus aparatos. El estetoscopio inventado por Laënecc (1781-1826) (Laënecc 1819), y la máquina de rayos X (que fueron descubiertos por Röntgen en 1895) son los más conocidos y populares. Tal vez habría que agregar al termómetro.

Pero se trata de un instrumental sencillo y, con excepción de los rayos X, casi manual. Algunos de ellos han encontrado el camino hacia el ámbito doméstico, nuestras casas: ¿quién no tiene, por si acaso, un termómetro?

Desde esos instrumentos la medicina ha avanzado a aparatos de una complejidad y de una apariencia impresionante, como impresionante también es su capacidad diagnóstica o terapéutica. Basta con que veamos un tomógrafo para que nos demos cuenta de eso.

¿Por qué es importante la historia de los aparatos en el estudio del desarrollo de una ciencia? Porque nos dan una información sobre varios aspectos, en primer lugar, sobre qué es 
lo que se quiere evaluar o medir con ese aparato, es decir cuáles son los grandes problemas y preocupaciones en una ciencia en un momento determinado de la historia. También porque conociendo y estudiando los aparatos podemos tener una idea del nivel de desarrollo tecnológico y científico de una sociedad determinada. Además, la calidad de los aparatos, la "fuerza" de ellos, y hasta quiénes los inventaron y quiénes los usaron, resultan de gran valor para tener una idea de cómo era la actividad científica y los responsables de ella en un momento determinado. De allí, su importancia desde el punto de vista histórico.

Hemos puesto el ejemplo de la medicina, en la cual precisamente se registra un impresionante desarrollo. De la generación de aparatos e instrumentos médicos del pasado son pocos los que han sobrevivido hasta hoy: los rayos $\mathrm{X}$ por ejemplo y el estetoscopio, ya antes mencionados. Otros han pasado a encontrar su lugar definitivo en los museos de historia de la medicina. Pero no podemos dejar de mencionar a uno más, al mismo tiempo tan común y tan temido: la inyección, que comenzó a ser muy discutida e investigada en sus posibilidades (junto con las transfusiones de sangre), desde 1650 (Ruisinger 2014).

La psicología también tiene sus aparatos: desde los sencillos tests mentales hasta las elaboradas escalas como las que creara David Wechsler para evaluar la inteligencia. Los puntajes y cocientes que ellos arrojan han ganado entretanto un prestigio tal que pueden determinar el futuro de una persona. Y, si dejamos de lado estos instrumentos, solo basta con que nos demos una vuelta por un laboratorio de psicología experimental bien dotado para que observemos allí la gran cantidad de aparatos que están presentes.

Tanto en medicina como en psicología esos aparatos, además de precisar información y confirmar presunciones, se convierten en irrefutable base para la toma de decisiones, de modo tal que el "ojo clínico" y la "intuición del psicólogo" han perdido mucho del valor que antes se les asignaba.

Los aparatos en todas las ciencias no solo responden a las necesidades de precisión y objetividad inherentes a todo saber que se precia de ser objetivo. Son también el resultado del avance progreso industrial: ¿habría podido Wundt proclamar que la suya era una "psicología experimental" si no hubiera contado en su laboratorio con el instrumental que le proporcionaba la firma Zimmerman, una casa especializada en instrumentos de alta precisión en fisiología y después en psicología? Los experimentos, los de Wundt y los de hoy, requieren casi siempre de un instrumental muy sofisticado que solo puede contarse allí donde la industria tiene la 
capacidad primero de idearlos (vía sus profesionales) y después de fabricarlos (Gundlach 2006).

\section{Conclusión}

Basta con lo anterior para poner en evidencia lo variado del arsenal metodológico que tiene a su alcance el historiador de la ciencia, entre ellos también el de la psicología.

Todo fenómeno social y todo hecho histórico encierran una gran complejidad. Lo que ocurre en nuestros agitados tiempos en el mundo de la ciencia, de la política, del arte, lo demuestra de modo palmario.

En el plano de la psicología eso es también evidente. Preguntémonos por qué en los últimos veinte años la psicología positiva ha alcanzado el predicamento del que hoy disfruta, y encontraremos que no se trata solo de una corriente psicológica, sino que también expresa, contextos sociológicos y económicos (una clase media cada vez más autoconsciente, con necesidades más sofisticadas y un mayor nivel de ingreso económico), pero igualmente antropológico (la felicidad no es una ilusión, sino un derecho al que todos podemos aspirar) y hasta teológicos (no hay nada después de la muerte, de modo que la gran meta de todos los seres humanos no es el Paraíso Terrenal, sino la mejor vida que uno pueda tener en este mundo.

El estudio de la historia de la psicología demanda paciencia, empatía, mente amplia, concentración e intuición.

Paciencia, porque muchas veces se requiere un minucioso, lento, trabajoso proceso de recolección de datos, desperdigados, ocultados (cuando no lamentablemente destruidos). De eso pueden dar fe quienes en el pasado querían estudiar antecedentes y desarrollos de la psicología en los países del mundo socialista y se encontraban con puertas cerradas, funcionarios poco colaboradores o hasta desembozadamente hostiles. Eso, felizmente, ha cambiado mucho desde el derrumbe del Muro de Berlín.

Empatía, sobre todo, en quienes emprenden estudios biográficos. Además de la sólida investigación que debe sustentar este tipo de estudios, se hace necesario "meterse" en la cabeza y en los sentimientos del biografiado, algo que se puede lograr revisando cartas, conversando con familiares y colegas. Pero, no cabe duda, una "pizca" de empatía siempre es necesaria. 
Repetimos: una “pizca”. Porque demasiada empatía puede al final ser peligroso para conservar una mente amplia.

Eso, mente amplia, es asimismo muy necesaria. Y muy especialmente en psicología. En su historia abundan descalificaciones: de los enemigos de Freud con respecto a él y de él con respecto a sus enemigos, pero también a sus disidentes (a los que él automáticamente clasificaba como enemigos); de los psicólogos soviéticos hacia los occidentales y viceversa. Una mente amplia permite conservar "la cabeza fría", dejar de atender a los calificativos y desprendernos de nuestros prejuicios.

Se requiere también concentración. Concentración en dos sentidos: en el sentido de una atención redoblada y enfocada en cada punto, en cada época, en cada coprotagonista. Pero concentración también como la dedicación a aspectos muy específicos, a determinados aspectos y eventos en la historia de la ciencia. Así, podemos poner como ejemplo el detenido estudio del XXII. Congreso Internacional de Psicología, celebrado en Leipzig en 1980 (Schönpflug \& Lüer 2011).

\section{Referencias}

Ackerknecht, E. (1964). Breve historia de la psiquiatría. Buenos Aires: EUDEBA.

Alarcón, R. (1982). Vigencia del pensamiento de Honorio Delgado en la psiquiatría contemporánea. Revista de Neuro-psiquiatría, 45, 127-151.

Ash, M. G. (1998). Gestalt psychology in German culture, 1890-1967: Holism and the quest for objectivity. Cambridge: Cambridge University Press.

Basadre, J. (1973). El azar en la historia y sus límites. Con un apéndice: La serie de probabilidades de la emancipación peruana. Lima: P. L. Villanueva.

Bernal, J. D. (1967). Historia social de la ciencia. Barcelona: Península.

De Beauvoir, S. (1949). Le deuxième sexe. París: Gallimard.

Borch-Jacobsen, M. (2011). Les patients de Freud. Destins. Auxerre Cedex: Sciences Humaines Éditions. 
Bordelois, I. (2006). Etimología de las pasiones. Buenos Aires: Libros del Zorzal.

Bowlby, J. (1990). Charles Darwin. A life. New York: Basic Books.

Browne, J. (2009). Charles Darwin. El poder del lugar. Una biografía. Valencia: Universitat de València.

Burnham, J. C. (2005). What is medical history. Cambridge, Reino Unido-Malden, MA, EEUU: Polity Press.

Celine, L.-F. (1968). Semmelweis. Madrid: Alianza Editorial.

Cluny, C. M. (2008). Atacama. Ensayo sobre la Guerra del Pacífico 1879-1883. México DF: Fondo de Cultura Económica.

Corr, P. J. (2016). Eysenck. A contradictory psychology. Londres-New York: Palgrave Macmillan.

Delgado, H. (1926). Sigmund Freud. Lima: C. F. Southwell

Eckart, W. U. \& Jütte, R. (2007). Medizingeschichte. Eine Einführung. Colonia: Böhlau Verlag.

Eisinger, J. (2011). Einstein on the road. New York: Prometheus Books.

Ellenberger, H. F. (1976). El descubrimiento del inconsciente. Historia y evolución de la psiquiatría dinámica. Madrid: Gredos.

Farcau, B. W. (2000). The ten cents war. Chile, Peru and Bolivia in the War of the Pacific, 1879-1884. Westport, Conn.: Greenwood Publishing Group.

Farmelo, G. (2009). The strangest man, The hidden life of Paul Dirac, mystic of the atom. New York: Basic Books.

Figueroa, G. (2014). Freud, Breuer y Aristóteles: catarsis y el descubrimiento del Edipo. Revista Chilena de Neuro-psiquiatría, 52 (4), 264-273.

Fraga, R. (2016). ¿Qué hubiera pasado si...” 2, Historia argentina contrafáctica? Buenos Aires: Ediciones B Argentina. 
Friedman, L. J. (1999). Identity's architect. A biography of Erik H. Erikson. New York: Scribner.

Gardner, H. (1995). Mentes creativas. Barcelona: Paidós.

Gardner, H. \& Laskin, E. (1998). Mentes líderes. Una anatomía del liderazgo. Barcelona: Paidós.

Gay, P. (1989). Freud. Una vida de nuestro tiempo. Barcelona: Paidós.

Geuter, U. (1992). The professionalization of psychology in Nazi Germany. New York: Cambridge University Press.

Graumann, C. F. \& Gergen, K. J., eds. (1996). Historical dimensions of psychological discourse. Cambridge: Cambridge University Press.

Gundlach, H. (2006). Was ist ein psychologisches Instrument? Berichte und Abhandlungen der Berlin-Brandenburgische Akademie der Wissenschaften, 11, 2779.

Hearnshaw, L. (1979). Cyril Burt, psychologist. Londres: Hodder and Stoughton.

Heinz, A. (2014). Der Begriff der psychischen Krankheit. Frankfurt: Suhrkamp.

Hergenhahn, B. R. (2011). Historia de la psicología. México DF: Cencage Learning.

Hirschmüller, A. (1990). The life and work of Josef Breuer: physiology and psychoanalysis. New York: New York University Press.

Iaccarino, M. (2003). Science and culture. Western science could learn a thing or two from the way science is done in other cultures. EMBO Reports [European Molecular Biology Organization], 4 (3), 220-223.

Isaacson, W. (2008). Einstein. Su vida y su universo. Barcelona: Debate.

Jacó-Vilela, A. M.; Arruda Leal Ferreira, A. \& Teixeira Portugal, F., orgs. (2005). História da psicología. Rumos e percursos. Rio de Janeiro: Nau.

Jamison, K. R. (1994). Touched with fire. Manic-depressive illness and the artistic temperament. New York: Free Press. 
Jaynes, J. (1987). El origen de la conciencia en la ruptura de la mente bicameral. México DF: Fondo de Cultura Económica.

Jones, E. (1976). Vida y obra de Sigmund Freud. Buenos Aires: Paidós, 3 vols.

Jones, J. H. (1997). Alfred C. Kinsey. A public/private life. New York: Norton.

Kamin, L. (1983). Ciencia y política del cociente intelectual. Madrid: Siglo XXI.

Karlauf, Th. (2007). Stefan George. Die Entdeckung des Charisma. Biographie. Munich: Karl Blessing.

Keynes, M. (1995). The personality of Isaac Newton. Notes and Records of the Royal Society of London, 49 (1), 1-56.

Koopmann, H. (2005). Thomas Mann-Heinrich Mann. Die ungleichen Brüder. Munich: Beck.

Kozulin, A. (1984). Psychology in utopia. Toward a social history of Soviet psychology. Cambridge, Mass: The MIT Press.

Laënecc, R. T. H. (1819). De l'Auscultation mediate ou Traité du Diagnostic des Maladies des Poumons et du Coeur. París. Brosson \& Chaudé.

Lamb, S. D. (2014). Pathologist of the mind. Adolf Meyer and the origins of American psychiatry. Baltimore: Johns Hopkins University Press.

Leahey, Th. H. (2005). Historia de la psicología. Principales corrientes en el pensamiento psicológico. México DF: Pearson Prentice Hall.

León, R. (2016-2017). Una vida rusa en la psicología: a propósito de una reciente biografía de Ivan P. Pavlov. Acta Herediana, 59, 80-89.

Lessing, D. (1978). El cuaderno dorado. Barcelona: Noguer.

Martin, B. (1981). The impact of research funding on curriculum. Ed info, nro. 4, Julio, 4549.

Maurois, A. (2005). En busca de Marcel Proust. Barcelona: Vergara. 
Meulders, M. (2010). Helmholtz. From Enlightenment to neuroscience. Cambridge, Mass., y Londres: The MIT Press.

Monod, J. (1970). El azar y la necesidad. Ensayo sobre la filosofía natural de la biología moderna. Barcelona: Barral.

Nussbaum, M. (1997). Justicia poética. La imaginación literaria y la vida pública. Santiago: Andrés Bello.

Nussbaum, M. (2010). Sin fines de lucro. Por qué la democracia necesita las humanidades. Buenos Aires: Katz.

Payne, M., comp. (2002). Diccionario de teoría crítica y estudios culturales. Buenos Aires: Paidós.

Phillips, A. (2014). Becoming Freud. The making of a psychoanalyst. New Haven y Londres: Yale University Press.

Pickren, W. E. \& Dewsbury, D. A., eds. (2007). Evolving perspectives on the history of psychology. Washington DC: American Psychological Association.

Pongratz, L. J. (1984). Problemgeschichte der Psychologie. Munich: Francke Verlag.

Popkin, R. H. (1990). Newton as a Bible scholar. En: Force, J. E. \& Popkin, R. H., Essays on the context, nature, and influence of Isaac Newton's theology, DordrechtBoston-Londres, Kluwer Academic Publishers, 103-118.

Postel, J. \& Quétel, C., comps. (1987). Historia de la psiquiatría. México DF: Fondo de Cultura Económica.

Prater, D. A. (1995). Thomas Mann: a life. Oxford: Oxford University Press.

Prochnik, G. (2014). El exilio imposible. Stefan Zweig en el fin del mundo. Barcelona: Ariel.

Rawls, J. (1995). Teoría de la justicia. México DF: Fondo de Cultura Económica.

Reidl Martínez, L. M. (2005). Celos y envidia: emociones humanas. México DF: Universidad Nacional Autónoma de México. 
Renouvier, Ch. (1945). Ucronía. La utopía en la historia. Bosquejo histórico apócrifo del desenvolvimiento de la civilización europea, no tal como ha sido, sino tal como habría podido ser. Buenos Aires: Losada, trd. de J. Ferrater Mora.

Roudinesco, E. (2015). Freud en su tiempo y en el nuestro. Barcelona: Debate.

Ruisinger, M. M. (2014). Injektionsspritze und Narkoseapparat. Zum Zusammenhang von Theorie und Praxis in der Medizin. En: Technoseum, ed., Herzblut. Geschichte und Zukunft der Medizintechnik, Darmstadt, Theiss, 24-39.

Said, E. (2003). Orientalismo. Barcelona: DeBolsillo.

Sater, W. F. (2007). Andean tragedy. Fighting the War of the Pacific, 1879-1884. Lincoln y Londres: University of Nebraska Press.

Schönpflug, W. (2000). Geschichte und Systematik der Psychologie. Ein Lehrbuch für das Grundstudium. Weinheim: Psychologie Verlags Union.

Schönpflug, W. \& Lüer, G. (2011). Psychologie in der Deutschen Demokratischen Republik: Wissenschaft zwischen Ideologie und Pragmatismus. Der XXII. Internationale Kongress für Psychologie 1980 in Leipzig, seine Vorgeschichte und Nachwirkungen. Wiesbaden: Verlag für Sozialwissenschaften.

Scholl Latour, P. 2002). Kampf dem Terror-Kampf dem Islam. Berlín: Propyläen.

Seymour, S. C. (2015). Cora Du Bois. Anthropologist, diplomat, agent. Lincoln-Londres: University of Nebraska Press.

Skidelsky, R. (2010). Keynes: the return of the master. New York: Public Affairs.

Smith, R. H., ed. (2008). Envy. Theory and research. Oxford: Oxford University Press.

Söderqvist, T. (2003). Science as autobiography: the troubled life of Niels Jerne. New Haven, Conn.: Yale University Press.

Street, W. R. (1994). A chronology of noteworthy events in American psychology. Washington DC: American Psychological Association. 
Szasz, Th. (1961). The myth of mental illness. Foundations of a theory of personal conduct. New York: Harper \& Row.

Todes, D. (2014). Ivan Pavlov. A Russian life in science. Oxford-New York: Oxford University Press.

Valosik, V. (2014). Arabic is blooming. For strategic, business, and cultural reasons, Arabic programs have grown rapidly at U. S. institutions -even surpassing some traditional favorites. International Educator, 2014 Language Supplement, 1-8.

Valsiner, J. (2012). A guided science. History of psychology in the mirror of its making. New Brunswick, USA-Londres: Transaction Publishers.

Von Neumann, J. \& Morgenstern, O. (1943). Theory of games and economic behavior. Princeton: Princeton University Press.

Westfall, R. S. (2006). Isaac Newton. Una vida. Madrid: Akal.

Woodward, W. R. (2015). Hermann Lotze. An intellectual biography. New York: Cambridge University Press.

Yarochevsky, M. G. (1979). La psicología del siglo XX. México DF: Grijalbo. 